\title{
Importance of Brain-Derived Neurotropic Factor in Substance Abuse
} Relapse

\author{
Alireza Khosravi ${ }^{1}$ and Saeed Bakhshani (iD ${ }^{1, *}$ \\ ${ }^{1}$ School of Medicine, Zahedan University of Medical Sciences, Zahedan, IR Iran \\ "Corresponding author: School of Medicine, Zahedan University of Medical Sciences, Zahedan, IR Iran. Email: saeedb984@gmail.com
}

Received 2020 May 27; Accepted 2020 May 30.

Keywords: Substance-Related Disorders, Relapse, Brain, Neurotrophic Factor

Addiction is a major public health problem (1). Repeated substance abuse relapse following each detoxification period is an important characteristic of the clinical course in people with addiction (2). Various factors, including psycho-bio-social factors, play a significant role in substance abuse and addiction $(3,4)$. It seems that substance abuse can lead to adaptation in neural circuits, which further complicates addiction (such as withdrawal symptoms and cravings) and may eventually increase the probability of relapse (5). Certain proteins in the brain are responsible for the growth and survival of brain neurons. These proteins are referred to as neurotrophic factors or neurotrophins. There are different types of neurotrophins in the brain, all referred to as brain-derived neurotrophic factors (BDNF), playing a role in the synaptic plasticity, learning (6), and neural adaptation induced by the repeated use of psychedelics such as cocaine (7). Neurotrophins are proteins that can easily enter or exit the brain; therefore, their blood levels can be easily measured through a simple test. When an undesirable event occurs and destroys one part of the brain, a large part of these proteins is also destroyed and therefore, their levels reduce in the human brain. For example, in those addicted to narcotics, the level of neurotrophins in the blood decreases, which is indicative of the degree of damage incurred to the brain. The lower the level of BDNF in blood compared to the normal state, the higher the damage to brain neurons. Addiction to psychedelics (e.g., methamphetamine) markedly reduces the level of BDNF in human blood.

The continuous use of narcotics stimulates adaptive mechanisms, thus inducing short-term and persistent changes in the functioning of neurons and neural networks sensitive to opioids. Some of these adaptive mechanisms include resistance, dependence, and sensitivity (8). During drug use, related behaviors become automatic and habitual, with weak voluntary control over them (9). Biochemical and molecular changes in the prefrontal cortex probably play a role in the loss of voluntary control in the progressive state of addiction, compulsive search (10, 11) for drug, decision-making on cognitive actions, and relapse. Those with addiction remain vulnerable years after drug use cessation. In these people, drug craving and the risk of relapse are often exacerbated by drug-related factors (11-14).

The abused drugs can take control of synapse plasticity mechanisms in the key brain circuits (including the mesolimbic dopamine system which is involved in motivation and reward behaviors) and activate them inappropriately in brain circuits $(14,15)$.

Addiction to narcotics leads to cognitive disorders, including memory loss and learning impairment. Heroin users have a poor performance in concentration, attention, fluency, and memory tests compared to healthy individuals. Rats chronically exposed to morphine also show impaired memory acquisition $(16,17)$. Accordingly, it seems that the chronic use of addictive drugs destroys the natural learning system and memory, leading to the maladaptive habitual behavior of compulsive search for drugs $(10,18)$. Moreover, compulsive and repeated use of drugs results from the pathologic involvement of natural molecular mechanisms involved in memory (14). The learning ability of morphine-dependent mice does not differ from that of controls in Morris water maze, but dependence on morphine impairs the recall ability of long-term spatial memory.

Moreover, morphine does not affect the acquisition and recall stages of short-term memory or motor activity of mice (19). Chronic use of and dependence on morphine can affect the $\operatorname{LTP}(20,21)$, which is probably one way through which the drug-related behavior is fortified 
by learning mechanisms. Chronic morphine use intensifies the LTP in the CA1 region of the hippocampus $(21,22)$. The tendency of synapses to higher plasticity under the effect of morphine can be regarded as chemical metaplasticity (20).

Cessation of chronic morphine use reduces the mice's efficiency in the water maze, as well as the LTP of the hippocampus, while re-use of morphine improves their LTP production and performance in the water maze. As a result, morphine-induced LTP modification may be associated with some unnatural behaviors in animals (13). Therefore, synaptic plasticity following chronic morphine use may occur inappropriately in brain circuits, including the dopaminergic neurons, thus affecting learning and memory (23). Synaptic plasticity of the hippocampus becomes dependent on morphine following chronic morphine use. In other words, the hippocampus function is adapted in the presence of morphine (24). The chronic use of narcotics, such as heroin and morphine, can affect learning and memory through reducing LTP (25). As a key structure involved in memory, the hippocampus is highly influenced by chronic drug use. These drugs lead to undesirable plasticity, dendritic atrophy, or neural degeneration in the hippocampus or the limbic-related structures, and bring about a $42 \%$ reduction in the neurogenesis of the hippocampal granule cells of adult mice (26, 27). Reduced neurogenesis in adult mice interferes with hippocampus-related learning and LTP expression $(16,26)$. Furthermore, chronic use of narcotics interferes with and regulates the intracellular neurotransmission pathways of neurotrophic growth factors, and thus interferes with neurons (12). Chronic prescription of narcotics or cocaine changes intracellular signaling pathways of neurotrophic factors, thereby disrupting the functioning and homeostatic role of these factors in maintaining new activities in the hippocampus, as well as synaptic functioning and neuron formation (28). The brain-derived neurotrophic factor is the most important brain neurotrophin, essential for strengthening the LTP of spatial memory. In animal models, BDNF seems to have semi-antidepressant effects in the hippocampus $(11,29)$. Finding effective ways for the prevention of narcotic-induced synaptic changes, and discovering how psychosocial factors interact with neurobiological factors (especially BDNF) in starting and continuing drug use can play a determining role in the treatment and prevention of relapse.

\section{Footnotes}

Authors' Contribution: None declared by author. Conflict of Interests: There is no conflict of interest.
Funding/Support: None declared by the author.

\section{References}

1. Ansari-Moghaddam A, Rakhshani F, Shahraki-Sanavi F, Mohammadi M, Miri-Bonjar M, Bakhshani NM. Prevalence and patterns of tobacco, alcohol, and drug use among Iranian adolescents: A metaanalysis of 58 studies. Child Youth Serv Rev. 2016;60:68-79. doi: 10.1016/j.childyouth.2015.11.018.

2. Washton AM, Stone-Washton N. Abstinence and relapse in outpatient cocaine addicts. J Psychoactive Drugs. 1990;22(2):135-47. doi: 10.1080/02791072.1990.10472539. [PubMed: 2197390].

3. Grau-Lopez L, Roncero C, Daigre C, Gonzalvo B, Bachiller D, RodriguezCintas L, et al. [Risk factors for relapse in drug-dependent patients after hospital detoxification]. Adicciones. 2012;24(2):115-22. Spanish. [PubMed: 22648314].

4. Preston KL, Epstein DH. Stress in the daily lives of cocaine and heroin users: Relationship to mood, craving, relapse triggers, and cocaine use. Psychopharmacology (Berl). 2011;218(1):29-37. doi: 10.1007/s00213011-2183-x. [PubMed: 21336579]. [PubMed Central: PMC3157572].

5. Nestler EJ, Aghajanian GK. Molecular and cellular basis of addiction. Science. 1997;278(5335):58-63. doi: 10.1126/science.278.5335.58. [PubMed: 9311927].

6. Aicardi G, Argilli E, Cappello S, Santi S, Riccio M, Thoenen H, et al. Induction of long-term potentiation and depression is reflected by corresponding changes in secretion of endogenous brain-derived neurotrophic factor. Proc Natl Acad Sci U S A. 2004;101(44):15788-92. doi: 10.1073/pnas.0406960101. [PubMed: 15505222]. [PubMed Central: PMC524856].

7. Dietz DM, Dietz KC, Nestler EJ, Russo SJ. Molecular mechanisms of psychostimulant-induced structural plasticity. Pharmacopsychiatry. 2009;42 Suppl 1:S69-78. doi: 10.1055/s-0029-1202847. [PubMed: 19434558]. [PubMed Central: PMC2734446].

8. Williams JT, Christie MJ, Manzoni O. Cellular and synaptic adaptations mediating opioid dependence. Physiol Rev. 2001;81(1):299-343. doi: 10.1152/physrev.2001.81.1.299. [PubMed: 11152760].

9. Kelley AE. Memory and addiction: shared neural circuitry and molecular mechanisms. Neuron. 2004;44(1):161-79. doi: 10.1016/j.neuron.2004.09.016. [PubMed:15450168].

10. Robbins TW, Everitt BJ. Limbic-striatal memory systems and drug addiction. Neurobiol Learn Mem. 2002;78(3):625-36. doi: 10.1006/nlme.2002.4103. [PubMed: 12559840].

11. Nestler EJ. Common molecular and cellular substrates of addiction and memory. Neurobiol Learn Mem. 2002;78(3):637-47. doi: 10.1006/nlme.2002.4084. [PubMed: 12559841].

12. Nestler EJ. Molecular basis of long-term plasticity underlying addiction. Nat Rev Neurosci. 2001;2(2):119-28. doi: 10.1038/35053570. [PubMed: 11252991].

13. Pu L, Bao GB, Xu NJ, Ma L, Pei G. Hippocampal long-term potentiation is reduced by chronic opiate treatment and can be restored by reexposure to opiates. J Neurosci.2002;22(5):1914-21. [PubMed: 11880521]. [PubMed Central: PMC6758897].

14. Wolf ME. Addiction: Making the connection between behavioral changes and neuronal plasticity in specific pathways. Mol Interv. 2002;2(3):146-57. doi: 10.1124/mi.2.3.146. [PubMed: 14993375].

15. Kauer JA, Malenka RC. Synaptic plasticity and addiction. Nat Rev Neurosci. 2007;8(11):844-58. doi: 10.1038/nrn2234. [PubMed: 17948030].

16. Eisch AJ, Barrot M, Schad CA, Self DW, Nestler EJ. Opiates inhibit neurogenesis in the adult rat hippocampus. Proc Natl Acad Sci U S A. 2000;97(13):7579-84. doi: 10.1073/pnas.120552597. [PubMed: 10840056]. [PubMed Central: PMC16588].

17. Salmanzadeh F, Fathollahi Y, Semnanian S, Shafizadeh M. Long-term potentiation as an electrophysiological assay for morphine dependence and withdrawal in rats: An in vitro study. J Neurosci Methods. 
2003;124(2):189-96. doi: 10.1016/s0165-0270(03)00016-5. [PubMed: 12706849].

18. Volkow ND, Fowler JS, Wang GJ, Goldstein RZ. Role of dopamine, the frontal cortex and memory circuits in drug addiction: Insight from imaging studies. Neurobiol Learn Mem. 2002;78(3):610-24. doi: 10.1006/nlme.2002.4099. [PubMed: 12559839].

19. Miladi Gorji H, Rashidy-Pour A, Fathollahi Y. Effects of morphine dependence on the performance of rats in reference and working versions of the water maze. Physiol Behav. 2008;93(3):622-7. doi: 10.1016/j.physbeh.2007.11.002. [PubMed:18067930].

20. Mansouri FA, Motamedi F, Fathollahi Y. Chronic in vivo morphine administration facilitates primed-bursts-induced long-term potentiation of Schaffer collateral-CA1 synapses in hippocampal slices in vitro. Brain Res. 1999;815(2):419-23. doi: 10.1016/s0006-8993(98)011482. [PubMed: 9878860].

21. Mansouri FA, Motamedi F, Fathollahi Y, Atapour N, Semnanian S Augmentation of LTP induced by primed-bursts tetanic stimulation in hippocampal CA1 area of morphine dependent rats. Brain Res.1997;769(1):119-24. doi:10.1016/s0006-8993(97)00608-2.[PubMed 9374279].

22. Racz B, Fuzesi M, Halasy K. The hippocampal opioidergic system: A comparative immunocytochemical study in four rodents. Neurobiology (Bp). 1998;6(4):429-41. [PubMed: 10220778].
23. Berke JD, Hyman SE. Addiction, dopamine, and the molecular mechanisms of memory. Neuron. 2000;25(3):515-32. doi: 10.1016/s08966273(00)81056-9. [PubMed: 10774721].

24. Bao G, Kang L, Li H, Li Y, Pu L, Xia P, et al. Morphine and heroin differentially modulate in vivo hippocampal LTP in opiatedependent rat. Neuropsychopharmacology. 2007;32(8):1738-49. doi: 10.1038/sj.npp.1301308. [PubMed: 17251910].

25. Ma MX, Chen YM, He J, Zeng T, Wang JH. Effects of morphine and its withdrawal on Y-maze spatial recognition memory in mice. Neuroscience. 2007;147(4):1059-65. doi:10.1016/j.neuroscience.2007.05.020. [PubMed: 17601672].

26. Eisch AJ, Mandyam CD. Drug dependence and addiction, II: Adult neurogenesis and drug abuse. Am J Psychiatry. 2004;161(3):426. doi: 10.1176/appi.ajp.161.3.426. [PubMed: 14992964].

27. Tamminga CA. Adult neurogenesis and drug abuse. Am J Psychiatry. 2004;161(3):426. doi: 10.1176/appi.ajp.161.3.426

28. Nestler EJ. Historical review: Molecular and cellular mechanisms of opiate and cocaine addiction. Trends Pharmacol Sci. 2004;25(4):210-8. doi: 10.1016/j.tips.2004.02.005. [PubMed: 15063085].

29. Yamada K, Mizuno M, Nabeshima T. Role for brain-derived neurotrophic factor in learning and memory. Life Sci. 2002;70(7):735-44. doi: 10.1016/s0024-3205(01)01461-8. [PubMed: 11833737]. 